\title{
A Research on Impact of Social Media on College Students in Chennai District
}

\author{
Elantheraiyan.P, S.Shankarkumar
}

\begin{abstract}
Social media is a rich source of infotainment for most of the people in the current scenario for huge chunk of literate people. Social serves as a vent and a platform for these people to elicit their thoughts, ideas, feelings and creativity. But too much of anything will have a negative impact and it might hamper your productivity, especially in the case of college students in Chennai you can hardly find a person who doesn't have an account in any of the social media like Facebook, Whatsapp, sharechat, Instagram etc. If you observe generally most of the college goers immerse themselves more on these social media and they become maniac over it in such away that for every 30 minutes on an average they would like to have a glimpse on the updates popping up on social media. Apart from college timings these social media swallows most of the student's productive time. This study reveals how the social media impacts the value time and distracts the students from their primary goal and how it creates havoc in their personal life.
\end{abstract}

Key words-Social media, glimpse and havocFacebook, WhatsApp share chat and Instagram.

\section{INTRODUCTION}

Social media is an undoubted medium through which many people share and educate themselves during the initial stages. But in the present days period of time spent and the impact that social media creates is huge than that of anyother medium like that of television,radio,newspaper etc. A technology always gives a huge comfort and flexibility at first and after a certain period of time the same blessing becomes a curse, when people especially students over indulge alot in such activities. Off late if we see the students academic performance and their socialization in the society is hampered due to their addiction towards social media. Till school days these people have a been streamlined to forcibly concentrate on their studies and somehow it works and helps them to come out with good marks ,but once they enter into the college their clutches are freed and they have ultimate freedom so that they fail to use it in a responsible manner. Apart from books and other academic related articles, the mobiles phones have become an inevitable part in every students life.In this techsavy society even academicians they update and communicate academic related stuffs to students via mobile phones .So it transforms the way students learn nowadays. Instead of carrying a huge number of books if they carry a cell phone they can easily capture and store academic related information a lot than in anyotherform,but very few students use it on a constructive

Revised Manuscript Received on September 10, 2019.

DR.Elantheraiyan. P, Assistant Professor, Veltech Rangarajan DR. Sagunthala R\&D Institute Of Science \& Technology, Avadi, Chennai, Tamilnadu, India.

(email: elantheraiyan@hotmail.com)

MR.S.Shankarkumar, RESEARCH SCHOLAR, Veltech Rangarajan DR. Sagunthala R\&D Institute Of Science \& Technology, Avadi, Chennai, Tamilnadu, India. mode whereas most of the students use it in such a way it pulls them out of the routine and become addicted towards social media .Initial stages the priority of social media is less but slowlyspreads it clutches in such away it the priority from the studies goes towards social media. Social media serves valuables and distraction on the same plate.Since students are more prone to distractions they go on the regressive mode rather than the progressive one. The same social media has lots positive things which can mould every student intoan intellectual. But the negatives in social medium have overshadowed the positives. If view on general most of the social media misguides the students and youngsters in the form of fake information.

\section{REVIEW OF LITERATURE}

According to Walton (2017) cyber bullying and social network sites creates depression among its users they by spoiling the mental and physical hygiene of the people.That to students community become a huge victim of such kind of hazards from social media which might spoil the whole society as a chain reaction.

According to Garcia (2016) students in California were surveyed and they output said that nearly half of the studypopulation had more than three accounts in carious social networking sites like facebook,instagram, snapchat,twitter, whatsapp etc. Such a kind of behavior distracts them from their studies and results in scoring low marks in their exams and sometimes it also spoils healthy relationships which is a huge headache for college goers where they unknowingly devalue a relationship with their friends due to their activity in social networking sites.

According to Dunn (2011) the active participation of college students in social networking sites may or may not fetch jobs. Because new age recruiters sometimes penetrate into the students page and observe their post and frame a picture of students whether they'll be suitable for the company or not. Which may sometimes give them a better leverage.

According to Tiffany Pempek\& Sandra L.Calvert(2009) College students spend 30 minutes on an average in a social networking sites.They feel that it's a place where they can vent out their feelings and creation to their friends with whom they had an pre-established relationship. Mostly they start with creating and posting something in social networking sites but instead of focusing on creativity, they end up in sharing other peoples thoughts and ideologies

Published By:

Blue Eyes Intelligence Engineering

$\&$ Sciences Publication 
which is a replica of their identity which they want to maintain.

According to Nyland (2007) there are five basic reasons for using social networking sites they are meeting new people,entertainment,maintaining relationships, social events and media creation. This habit starts as fun and a knowledge sharing activity in the beginning and finally it takes a U-turn and makes its users as an addict to it there by spoiling their near and dear ones life in a direct or indirect manner.

\section{OBJECTIVES}

$>$ To study about the average time spent by the students on social media.

To have an insight about the students usage purpose and social media behavior.

$>$ To study about the impact of social media on students academic performance.

$>\quad$ To examine the students personal and social media relationships

To find out the suitable measures to get rid of social media addiction.

\section{SCOPE OF THE STUDY}

- The study throws light on the craving for social media among students.

- The study creates an awareness about the havoc created by social media

- The study helps in filling the potholes created by social media among the student community.

- The study paves the way for further research and serves as a record in future.

\section{LIMITATIONS}

$\checkmark \quad$ The respondents response may be biased and may change over time

$\checkmark \quad$ The findings pertains only to Chennai district and cannot be taken as a generalized one.

$\checkmark \quad$ Within the short span its hard to give accurate results, but approximation is possible.

\section{RESEARCH METHODOLOGY}

Research Design -Descriptive Research

Sampling Technique - Convenience Sampling

Sample Size -110 Sample

Data Collection: Primary and Secondary Method

Research Tool: Well Structured Questionnaire

Statistical Tools Applied: Percentage,Chi-Square, Spearman Rank Correlation and weighted average method

\section{DATA ANALYSIS AND INTERPRETATION RESULTS}

7.1 SOCIAL MEDIA ADDICTION WITH RESPECT TO GENDER

\begin{tabular}{|c|c|c|c|}
\hline S.No & Particulars & Respondents & Percentage \\
\hline 1. & MALE & 52 & $47 \%$ \\
\hline 2. & FEMALE & 58 & $53 \%$ \\
\hline & TOTAL & $\mathbf{1 1 0}$ & $\mathbf{1 0 0} \%$ \\
\hline
\end{tabular}

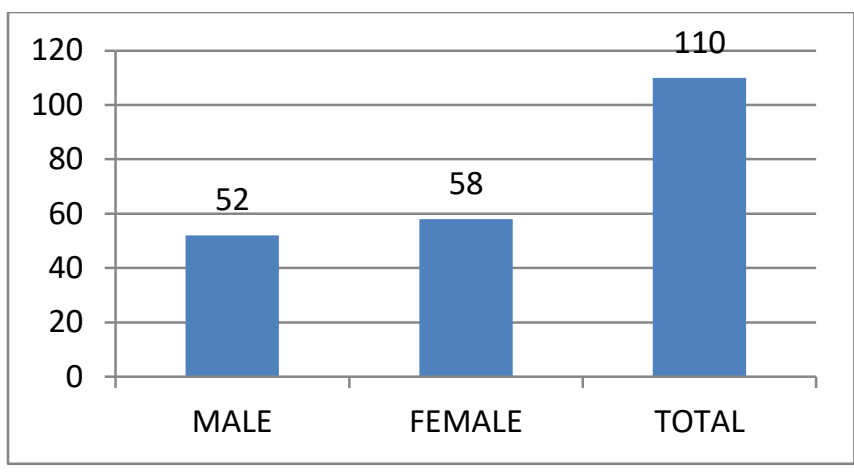

Inference:From the above table its inferred that female students $53 \%$ of nowadays are addicted to social media than male students $47 \%$.

7.2 USAGE OF SOCIAL MEDIA AMONG COLLEGE UG PG AND RESEARCH STUDENTS

\begin{tabular}{|c|c|c|c|}
\hline S.No & Particulars & Respondents & Percentage \\
\hline 1. & UG & 70 & $63 \%$ \\
\hline 2. & PG & 30 & $27 \%$ \\
\hline 3. & RESEARCH & 10 & $10 \%$ \\
\hline & TOTAL & $\mathbf{1 1 0}$ & $\mathbf{1 0 0} \%$ \\
\hline
\end{tabular}

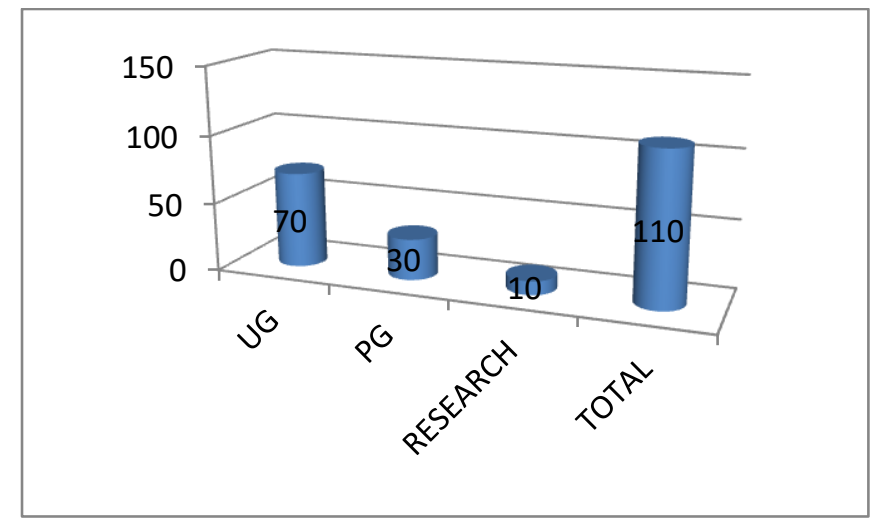

Inference:Its inferred that UG students $63 \%$ social media usage is more than PG 27\% and Research students $10 \%$.

\subsection{AVERAGE TIME SPENT ON SOCIAL MEDIA}

\begin{tabular}{|c|c|c|c|}
\hline S.No & Particulars & Respondents & Percentage \\
\hline 1. & 30 minutes & 13 & $12 \%$ \\
\hline 2. & 1 hour & 19 & $17 \%$ \\
\hline 3. & More than 1 hour & 78 & $71 \%$ \\
\hline & TOTAL & $\mathbf{1 1 0}$ & $\mathbf{1 0 0 \%}$ \\
\hline
\end{tabular}




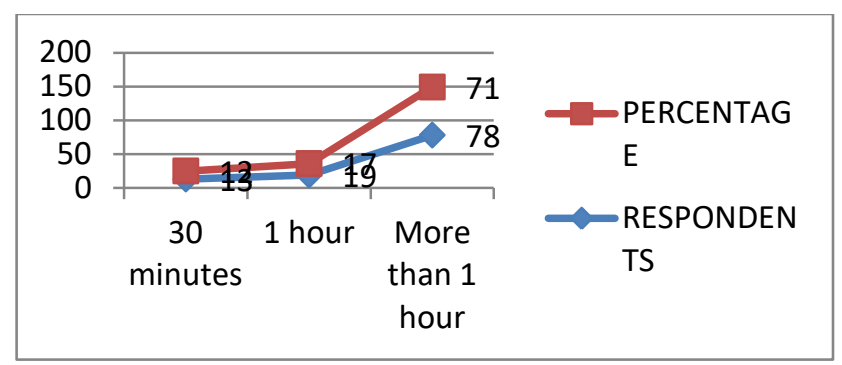

Inference:Itsunderstood from the above table that most of the respondents spend more than an hour $71 \% .17 \%$ and $12 \%$ of the respondents spend an hour and 30 minutes in social media on an average.

\subsection{MOST PREFERRED SOCIAL MEDIUM}

\begin{tabular}{|c|l|c|c|}
\hline S.No & \multicolumn{1}{|c|}{ Particulars } & Respondents & Percentage \\
\hline 1. & Face Book & 30 & $27 \%$ \\
\hline 2. & Wats App & 55 & $50 \%$ \\
\hline 3. & Tik Tok & 15 & $14 \%$ \\
\hline 4. & Instagram & 7 & $6 \%$ \\
\hline 5. & Others & 3 & $3 \%$ \\
\hline & TOTAL & $\mathbf{1 1 0}$ & $\mathbf{1 0 0 \%}$ \\
\hline
\end{tabular}

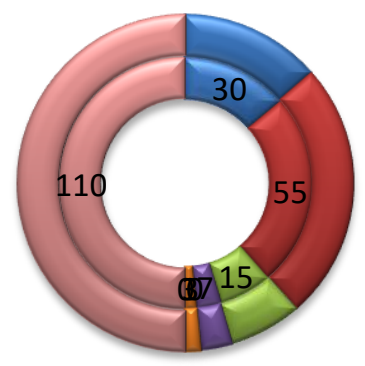

Face
Book
Wats
App
Tik
Tok
Instagr
am

Inference: Itsinferred that the majority of the respondents use wats app 55\% and Facebook $27 \%$ While 14\% and 6\% of them use Tik Tok and Instagram and $3 \%$ of the respondents use other social medium respectively.

\subsection{SOCIAL MEDIA USAGE PURPOSE}

\begin{tabular}{|c|l|c|c|}
\hline S.No & \multicolumn{1}{|c|}{ Particulars } & Respondents & Percentage \\
\hline 1. & Knowledge gaining & 8 & $7 \%$ \\
\hline 2. & Information Sharing & 24 & $22 \%$ \\
\hline 3. & Social Identity & 18 & $16 \%$ \\
\hline 4. & Entertainment & 46 & $42 \%$ \\
\hline 5. & Stress Buster & 14 & $13 \%$ \\
\hline & TOTAL & $\mathbf{1 1 0}$ & $\mathbf{1 0 0 \%}$ \\
\hline
\end{tabular}

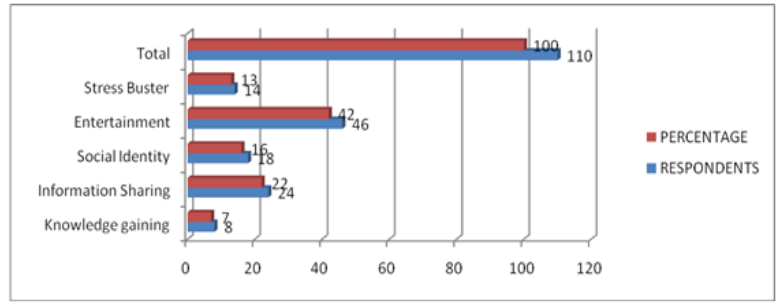

Inference: Majority $42 \%$ of the students use social media for entertainment, $22 \%$ use it for information sharing, $16 \%$ of students use it for social identity. $13 \%$ and $7 \%$ of them use it as stress buster and knowledge gaining.

7.6 IMPACT OF SOCIAL MEDIA ON STUDENTS ACADEMIC PERFORMANCE

\begin{tabular}{|c|l|c|c|}
\hline S.No & Particulars & Respondents & Percentage \\
\hline 1. & POSITIVE & 53 & $48 \%$ \\
\hline 2. & NEGATIVE & 57 & $52 \%$ \\
\hline & TOTAL & $\mathbf{1 1 0}$ & $\mathbf{1 0 0} \%$ \\
\hline
\end{tabular}

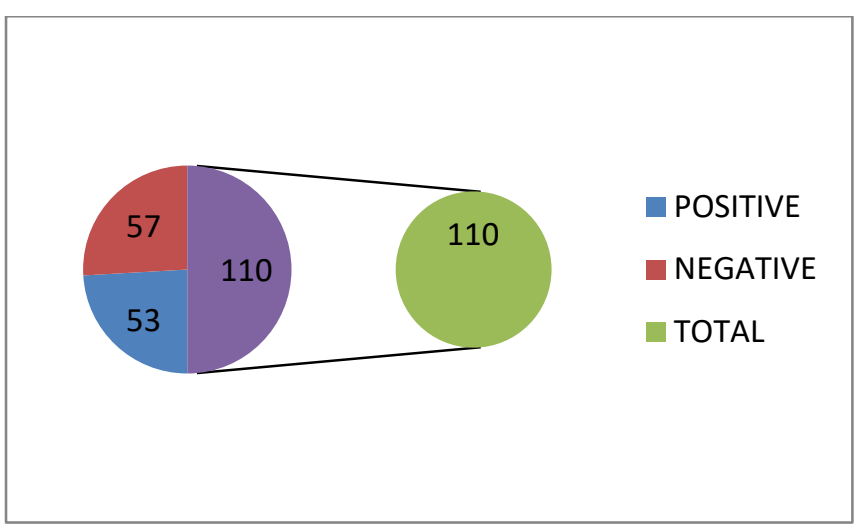

Inference: From the above table its concluded that $52 \%$ of the students responded for negative impact and $48 \%$ of them responded that its has a positive impact on their academic performance.

7.7 IMPACT OF SOCIAL MEDIA ON INTERPERSONAL RELATIONSHIP

\begin{tabular}{|c|c|c|c|}
\hline S.No & Particulars & Respondents & Percentage \\
\hline 1. & YES & 68 & $62 \%$ \\
\hline 2. & NO & 42 & $38 \%$ \\
\hline & TOTAL & $\mathbf{1 1 0}$ & $\mathbf{1 0 0} \%$ \\
\hline
\end{tabular}




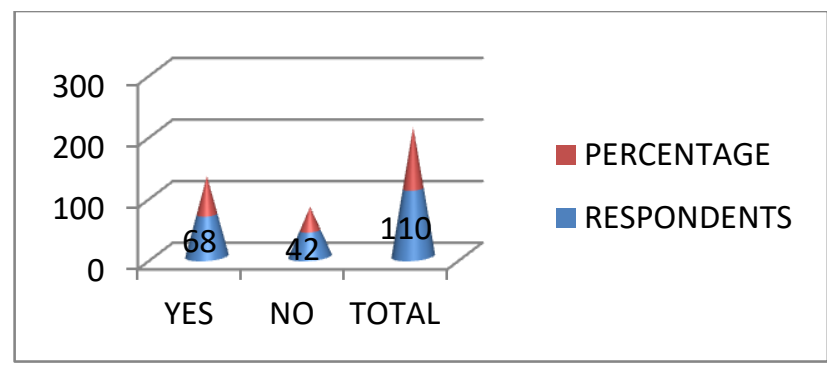

Inference:Its concluded from the above table that $62 \%$ of the students say that social media affects their interpersonal relationship and $38 \%$ of them say it doesn't affect.

\subsection{CHI-SQUARE ANALYSIS}

Testing the relationship between the time spent on social media and how its affects the students interpersonal relationship.

\begin{tabular}{|c|l|c|c|c|}
\hline S,No & \multirow{2}{*}{ Average Time Spent } & \multicolumn{4}{|c|}{ Students Interpersonal relationship impact } \\
\cline { 3 - 5 } & & YES & NO & TOTAL \\
\hline 1 & 30 min & 13 & 7 & 20 \\
\hline 2 & 1 hour & 25 & 25 & 50 \\
\hline 3 & More Than 1 hour & 30 & 10 & 40 \\
\hline & TOTAL & 68 & 42 & 110 \\
\hline
\end{tabular}

\begin{tabular}{|c|c|c|c|c|c|}
\hline S.No & $\begin{array}{l}\text { Observed } \\
\text { Frequency }\end{array}$ & $\begin{array}{l}\text { Expected } \\
\text { Frequency }\end{array}$ & O-E & $\mathbf{( O - E - 0 . 5}^{\mathbf{2}}$ & $\mathbf{( O - E - 0 . 5}^{2} \mathbf{~ / E}$ \\
\hline 1 & 13 & 12.36 & 0.64 & 0.4096 & 0.0331 \\
\hline 2 & 25 & 30.90 & -5.9 & 34.81 & 1.1265 \\
\hline 3 & 30 & 24.72 & 5.28 & 27.04 & 1.0929 \\
\hline 4 & 7 & 7.63 & -0.63 & 0.3969 & 0.05201 \\
\hline 5 & 25 & 19.09 & 5.91 & 34.92 & 1.82922 \\
\hline 6 & 10 & 15.27 & -5.27 & 27.77 & 1.8185 \\
\hline
\end{tabular}

$$
=5.95223
$$

The calculated value $=5.95223$

Degrees of freedom $\mathrm{v}=(\mathrm{r}-1)(\mathrm{c}-1)$

$$
\begin{aligned}
& =(3-1)(2-1) \\
& =2
\end{aligned}
$$

The Tabulated values $\psi 2 \alpha=0.05$ for 2 difference is 5.99. Since the calculated value is less than the table value.Hence $\mathrm{H} 0$ accepted and $\mathrm{H} 1$ is rejected.

Inference: Since the calculated value is less than the table value. H0accepted and $\mathrm{H} 1$ is rejected. Hence there is no significant difference between the time spent on social media and its impact on students Interpersonal relationships.

\subsection{WEIGHTED AVERAGE METHOD}

Weighted Average method is used to find out which social medium is the most preferred one.

\begin{tabular}{|c|l|c|c|c|}
\hline S.No & \multicolumn{1}{|c|}{ Particulars } & $\begin{array}{c}\text { Weighted } \\
\text { Average }\end{array}$ & Respondents & WiXi \\
\hline 1. & Whats App & 5 & 55 & 275 \\
\hline 2. & Face Book & 4 & 30 & 120 \\
\hline 3. & Tik Tok & 3 & 15 & 45 \\
\hline 4. & Instagram & 2 & 7 & 14 \\
\hline 5. & Others & 1 & 3 & 3 \\
\hline & TOTAL & & $\mathbf{1 1 0}$ & $\mathbf{4 5 7}$ \\
\hline
\end{tabular}

\section{$\sum \mathrm{WiXi} / \sum \mathrm{Wi}=457 / 110=4.15=4$}

Inference: From the above table its inferred that what app has more weighted scores and the most preferable medium than face book 120, Tiktok 45,Instagram 14 others 3 respectively.

\subsection{OSPEARMAN RANK CORRELATION}

\begin{tabular}{|c|c|c|c|c|c|c|}
\hline S.No & Social Media (Xi) & Rank & Purpose (Yi) & Rank & $\mathrm{D}_{1}=\mathrm{Xi}-\mathrm{Yi}$ & $\sum \mathbf{D}_{1}{ }^{2}$ \\
\hline 1. & Face Book & 2 & Knowledge gaining & 5 & -3 & 0 \\
\hline 2. & Wats App & 1 & Information Sharing & 2 & -1 & 1 \\
\hline 3. & Tik Tok & 3 & Social Identity & 3 & 0 & 0 \\
\hline 4. & Instagram & 4 & Entertainment & 1 & 3 & 9 \\
\hline 5. & Others & 5 & Stress Buster & 4 & 1 & 1 \\
\hline & TOTAL & & & & & 20 \\
\hline
\end{tabular}

This is used to find out the correlation between the usage purpose of social media and the most preferred social media

Since $\mathrm{N}=5$ and $\sum \mathrm{D} 12=19$ we need to apply the formula we get

$$
\begin{aligned}
\mathrm{R} & =1-6 \sum \mathrm{d} 2 / \mathrm{n}(\mathrm{n} 2-1) \\
& =1-6 \times 20 / 5(52-1) \\
& =1-0 \\
& =0
\end{aligned}
$$

Inference: Its concluded from the above calculation that $\mathrm{R}$ value is zero.Hence zero indicates that there is no association in ranks between the most preferred social media and the purpose of its usage. Hence $\mathrm{H} 0$ null hypothesis can be accepted since there is no correlation.

\section{VIII.. FINDINGS}

A majority female student $53 \%$ of nowadays are addicted to social media than male students who are $47 \%$. A huge chunk of UG students $63 \%$ use social media more than PG $27 \%$ and Research students of $10 \%$.

Its inferred that most of the respondents spend more than an hour $71 \% .17 \%$ and $12 \%$ of the respondents get stuck for an hour and 30 minutes in social media respectively on an average.

A lot of respondents prefer whats app $55 \%$ and facebook $27 \%$ While $14 \%$ and $6 \%$ of them use Tik Tok and Instagram and $3 \%$ of the respondents use other social medium was recorded.

Majority $42 \%$ of social media usage is for entertainment, $22 \%$ usage is for information sharing, $16 \%$ of students use it as social identity regognition. $13 \%$ and $7 \%$ of them use it as stress buster and knowledge gaining purpose.

Its has been concluded that $52 \%$ and $48 \%$ of the students responded thatsocial media has impacted positively and negatively in their academic performance.

A dominant $62 \%$ of the students say that social media affects their interpersonal relationship considerably and $38 \%$ of them say it doesn't affect.

In Chi square test there is no significant difference between the time spent on social media and its impact on students interpersonal relationships.

In weighted average method whatapp has more weighted scores 275 and the most preferable medium than face book 120, Tiktok 45,Instagram 14 others 3 respectively.

In Spearman rank correlation there is no association or correlation in ranks between the most preferred social media and the purpose of its usage.

Published By: 


\section{SUGGESTIONS}

The yesteryear students were much more comfortable compared to the current generation because of the distractions that the technological world delivered to them in the name of exposure.Now a days most of the college goers have mobile phones which is almost like a sixth finger which is inseparable from them.Every invention is a double edged sword which has its own pros and cons.These millenials who are born after 2000s have a great access to the technological gadgets.We as a society should always keep an eye on the students welfare. These students are very much involving in the social media.Involving in social media isn't a wrong one but when it becomes an addiction were the social media consumes a huge chunk of time .Finally the students are left with sparse time to concentrate on their studies, that too if we notice properly in between the studies these people without focus always keep an eye on the social media thereby they lose the time to study and their academic performance declines. Even the social media educates a lot from the academic part but they students neglect it and concentrate only on fantasy part where lose their precious time and also their creativity.Most of the information shared in the social media is not trust worthy but it kindles the emotion of the students and guide them in the wrong way. These millennial students don't have mentor to guide them properly on this issue.The students are tomorrows future they need to be educated properly.If the indulgence in the social media is unavoidable the college facultyneed to take stiff as well as sensible measures to prevent them from over indulging in social media activity else they need to channelize the activity in the social media platform where they can learn a lot sensibly and use it in an appropriate manner.

\section{CONCLUSION}

Our Students are our asset and nation builders of tomorrow.In an informational technological world students in a metropolitan city like Chennai they're meant to achieve a lot in real world than in the reel world like that of social media.These college students in the Chennai city should be taught the limits of participation in social media activity.There is a clear demarcation between exposure and eccentric,afflitiation and addiction this should be taught to our students, moreover bad and unwanted things dominate in the social media than good things. They should be guided in such away to tune themselves for good things in social media and how to use them constructively.Very few students use this social media as a learning platform where theyuse it as a launch pad to showcase their talents and market themselves in this competitive environment.Thewell developed nations knows the perils of these social media and tune their students in such away to improve the students career constructively. But our students are caught in a booby trap where they're made to spend a lot of time on just for the sake of time passing and entertainment. Moreover the over indulgence in social media isolate them from their parents and make them think and act on the individual basis rather than the collective basis. Sometimes the contents thrown on the social media is filthy in such away it corrupts the quality of thoughts of the students and makes their life miserable.
Moreover the educational institutes along with parents and societies support should conduct awareness and educate the students on the ethical and fruitful usage of social media so that they can have a bright future.

\section{REFERENCES}

1. Www.ssrn.com

2. www.dspace.ewubd.edu

3. www.shodganga.com

4. www.humanresourcesmba.net 